\title{
Prostate Paraganglioma
}

National Cancer Institute

\section{Source}

National Cancer Institute. Prostate Paraganglioma. NCI Thesaurus. Code C161612.

A parag ang lioma that affects the prostate gland. 